\title{
STUDI KELAYAKAN PENYELENGGARAAN BUS KAMPUS ATMA JAYA BABARSARI YOGYAKARTA
}

\author{
Imam Basuki \\ Program Studi Teknik Sipil \\ Universitas Atma Jaya Yogyakarta \\ Jln. Babarsari No. 44, Yogyakarta \\ imbas2004@gmail.com
}

\author{
Eunike Maresa Macpal \\ Program Studi Teknik Sipil \\ Universitas Atma Jaya Yogyakarta \\ Jln. Babarsari No. 44, Yogyakarta \\ ike.mcpal@gmail.com
}

\begin{abstract}
One of the causes of traffic congestion in the Babarsari area is the existence of Atma Jaya University in Yogyakarta. To reduce congestion, a feasibility study was conducted to provide campus buses. Quantitative analysis method is done by collecting primary and secondary data. Then the data is analyzed for the track plan, fleet number, vehicle operating costs, and campus bus operational schedules. From the results of the analysis, 3 bus service routes are planned for the Atma Jaya Yogyakarta campus, located on Jalan Babarsari. The campus bus is planned to use vehicles with a capacity of 30 passengers, operates between 06:00 to 18:00, circulation time for each route is 51 minutes, 47 minutes, and 50 minutes, with each route having a headway of 15 minutes and the number of vehicles are 11 units. The calculation results show that the Vehicle Operating Costs are Rp14,020.62/Bus-km. The annual fee for students is Rp343,625.71 and is planned to be part of fixed school fees or in collaboration with banking Corporate Social Responsibility.
\end{abstract}

Keywords: campus bus, vehicle operating costs, time of circulation, traffic congestion

\begin{abstract}
Abstrak
Salah satu penyebab kemacetan lalu lintas di kawasan Babarsari adalah keberadaan Universitas Atma Jaya Yogyakarta. Untuk mengurangi kemacetan, dilakukan studi kelayakan untuk menyelenggarakan bus kampus. Metode analisis secara kuantitatif dilakukan dengan pengumpulan data primer dan data sekunder. Selanjutnya data dianalisis untuk rencana jalur, jumlah armada, biaya operasional kendaraan, dan jadwal operasional bus kampus. Dari hasil analisis, direncanakan 3 rute layanan bus menuju kampus Atma Jaya Yogyakarta yang terletak di Jalan Babarsari. Penyelenggaraan bus kampus ini direncanakan menggunakan kendaraan dengan kapasitas 30 penumpang, beroperasi antara pukul 06.00 hingga pukul 18.00, waktu sirkulasi untuk setiap rute berturut-turut adalah 51 menit, 47 menit, dan 50 menit, dengan setiap rute memiliki headway sebesar 15 menit, dan jumlah kendaraan adalah 11 unit. Hasil perhitungan menunjukkan bahwa Biaya Operasional Kendaraan adalah Rp14.020,62/Bus-km. Biaya tahunan untuk mahasiswa adalah Rp343.625,71 dan direncanakan menjadi bagian dari biaya sekolah tetap atau bekerja sama dengan Corporate Social Responsibility perbankan.
\end{abstract}

Kata-kata kunci: bus kampus, biaya operasional kendaraan, waktu sirkulasi, kemacetan lalu lintas

\section{PENDAHULUAN}

Kawasan Babarsari Yogyakarta merupakan suatu kawasan pusat kegiatan penarik pergerakan, yang berupa pertokoan, sekolah atau kampus, hotel, perkantoran, dan mall. Pergerakan lalu lintas di kawasan Babarsari, karena tingginya tarikan yang ada, mengakibatkan kepadatan kendaraan bermotor semakin tinggi. Kemacetan dan antrian panjang dalam waktu tertentu menjadikan kawasan tersebut rawan kecelakaan. Efek lain dari adanya banyaknya pergerakan dan volume lalu lintas yang tinggi, serta didominasi oleh kendaraan bermotor, adalah permasalahan polusi dan kenyamanan. 
Universitas Atma Jaya Yogyakarta (UAJY) merupakan salah satu dari 4 universitas yang ada di Babarsari. Gedung Universitas Atma Jaya Yogyakarta yang berlokasi di Babarsari terdiri atas 3 tempat, dengan jumlah mahasiswa sebanyak 8.667, yang tersebar di 5 fakultas dan program pascasarjana. Untuk mengurangi volume lalu lintas dan volume parkir dapat dilakukan langkah pembatasan atau pelarangan kendaraan sehingga pelaku perjalanan akan beralih ke angkutan umum. Namun pembatasan atau pelarangan tersebut juga berpotensi untuk memindahkan titik-titik parkir di sekitar kampus.

Salah satu pilihan transportasi yang memungkinkan adalah diadakannya bus kampus. Dengan diselenggarakan bus kampus sebagai sarana transportasi yang khusus melayani mahasiswa Universitas Atma Jaya Yogyakarta di Babarsari, diharapkan bus kampus tersebut menjadi angkutan yang efisien, tertata, dan teratur sesuai dengan kebutuhan mahasiswa. Layanan bus direncanakan mempunyai trayek yang menghubungkan setiap gedung fakultas di Universitas Atma Jaya Yogyakarta yang ada di Babarsari. Studi kelayakan penyelenggaraan bus kampus Universitas Atma Jaya di Babarsari, Yogyakarta, ini dilakukan agar dapat memberikan rekomendasi yang dapat dijadikan bahan pertimbangan dalam pengembangan infrastruktur transportasi di kawasan Universitas Atma Jaya Yogyakarta, di Babarsari.

\section{KAJIAN PERUNDANGAN}

Dalam Undang-Undang Nomor 22 Tahun 2009, tentang Lalu Lintas dan Angkutan Jalan, disebutkan bahwa lalu lintas dan angkutan jalan adalah satu kesatuan sistem yang terdiri atas lalu lintas, angkutan jalan, jaringan lalu lintas dan angkutan jalan, prasarana lalu lintas dan angkutan jalan, kendaraan, pengemudi, pengguna jalan, serta pengelolaannya. Secara rinci lalu lintas dan angkutan jalan diselenggarakan dengan tujuan:

1) terwujudnya pelayanan lalu lintas dan angkutan jalan yang aman, selamat, tertib, lancar, dan terpadu dengan moda angkutan lain untuk memajukan kesejahteraan umum, memperkukuh persatuan dan kesatuan bangsa, serta mampu menjunjung tinggi martabat bangsa;

2) terwujudnya etika berlalu lintas dan budaya bangsa; dan

3) terwujudnya penegakan hukum dan kepastian hukum bagi masyarakat.

Peraturan Pemerintah Nomor 74 tahun 2014, tentang Angkutan Jalan, membagi angkutan orang dengan kendaraan bermotor umum menjadi 2, yakni: (1) angkutan orang dengan kendaraan bermotor umum dalam trayek; dan (2) angkutan orang dengan kendaraan bermotor umum tidak dalam trayek. Jenis Angkutan orang dengan kendaraan bermotor umum dalam trayek terdiri atas: (a) angkutan lintas batas negara; (b) angkutan antar-kota antar-provinsi; (c) angkutan antar-kota dalam provinsi; (d) angkutan perkotaan; dan (e) angkutan perdesaan. Pelayanan angkutan orang yang disebutkan harus memenuhi kriteria, seperti memiliki rute tetap dan teratur, terjadwal, berawal, berakhir, dan menaikkan atau menurunkan penumpang di terminal untuk angkutan antarkota dan lintas batas negara, serta menaikkan dan menurunkan penumpang pada tempat yang telah ditentukan untuk angkutan 
perkotaan dan perdesaan (terminal, halte, rambu pemberhentian kendaraan bermotor umum). Sedangkan jenis angkutan orang dengan kendaraan bermotor umum tidak dalam trayek terdiri atas: (a) angkutan orang dengan menggunakan taksi; (b) angkutan orang dengan tujuan tertentu; (c) angkutan orang untuk keperluan pariwisata; dan (d) angkutan orang di kawasan tertentu. Untuk angkutan orang dengan kendaraan bermotor umum tidak dalam trayek, jadwal pelayanan menyesuaikan dengan kebutuhan dan diserahkan kepada pengelola. Namun jenis kendaraan yang digunakan diatur sesuai dengan jenis angkutan yang dilayani. Dalam Pasal 43 disebutkan bahwa pelayanan angkutan orang dengan tujuan tertentu merupakan angkutan yang melayani paling sedikit meliputi antar-jemput, keperluan sosial, atau karyawan, sehingga angkutan sekolah atau bus kampus termasuk dalam angkutan orang dengan tujuan tertentu.

Sebenarnya dalam Peraturan Direktur Jenderal Perhubungan Darat Nomor SK.967/AJ.202/DRJD/2007, tentang Pedoman Teknis Penyelenggaraan Angkutan Sekolah, masalah angkutan sekolah sudah diatur. Angkutan antar-jemput anak sekolah adalah angkutan yang khusus melayani siswa sekolah dengan asal dan atau tujuan perjalanan tetap, yaitu dari dan ke sekolah yang bersangkutan.

Dalam Peraturan Menteri Perhubungan Republik Indonesia Nomor PM 117 Tahun 2018, tentang Penyelenggaraan Angkutan Orang Tidak Dalam Trayek, angkutan sekolah diatur dalam Pasal 21. Angkutan sekolah merupakan pelayanan angkutan yang disediakan untuk mengangkut siswa sekolah dari dan ke lokasi sekolah. Angkutan sekolah dapat menggunakan: (a) kendaraan milik sekolah, (b) kendaraan umum yang disewa dari Perusahaan Angkutan Umum, atau (c) kendaraan umum yang dimiliki oleh Pemerintah Daerah.

\section{METODE PENELITIAN}

Data primer yang digunakan pada penelitian ini merupakan data yang diperoleh langsung di lapangan dengan melakukan survei. Data tersebut meliputi:

1) karakteristik calon penumpang, yaitu jenis kelamin dan usia;

2) karakteristik perjalanan penumpang, yaitu tempat tinggal mahasiswa, fakultas mahasiswa, dan moda transportasi yang digunakan;

3) pendapat responden terhadap rencana pengoperasian bus kampus, yaitu kesediaan menggunakan bus kampus Universitas Atma Jaya Yogyakarta; dan

4) panjang lintasan rute bus kampus, yaitu survei ke jalan yang akan menjadi rute.

\section{Kecukupan Jumlah Responden}

Untuk memperoleh data primer dilakukan survei dengan alat bantu kuesioner. Sebelum penyebaran kuesioner, analisis ukuran sampel dan distribusinya ditentukan untuk setiap fakultas. Ukuran sampel ditentukan dengan menggunakan rumus Slovin (Basuki et al., 2019) sebagai berikut: 


$$
\mathrm{n}=\frac{\mathrm{N}}{\mathrm{N}(\mathrm{e})^{2}+1}
$$

dengan:

$\mathrm{n}$ = ukuran sampel;

$\mathrm{N}=$ jumlah anggota dalam populasi; dan

$\mathrm{E}=$ tingkat kesalahan/error tolerance (dalam hal ini 5\%).

Berdasarkan data yang didapat, jumlah anggota dalam populasi adalah sebanyak 8.667 mahasiswa aktif, sehingga diperoleh ukuran sampel sebesar:

$$
\begin{aligned}
\mathrm{n} & =(8.667) /\left(8,667 *(0,05)^{\wedge} 2+1\right) \\
& =382,3536 \approx 400
\end{aligned}
$$

Setelah mendapatkan ukuran sampel, selanjutnya sampel dibagi ke setiap populasi fakultas yang ada di Universitas Atma Jaya Yogyakarta Babarsari secara proporsional. Hasil distribusi sampel ini ditunjukkan pada Tabel 1.

Tabel 1 Jumlah Responden

\begin{tabular}{clrrc}
\hline No. & Unit Kerja & Populasi & $\begin{array}{c}\% \\
\text { Populasi }\end{array}$ & $\begin{array}{c}\text { Jumlah } \\
\text { Responden }\end{array}$ \\
\hline 1 & Akuntansi & 1.465 & 16,90 & 68 \\
2 & Manajemen & 1.379 & 15,91 & 64 \\
3 & Teknobiologi & 435 & 5,02 & 20 \\
4 & Ekonomi Pembangunan & 258 & 2,98 & 12 \\
5 & Ilmu Komunikasi & 1.231 & 14,20 & 57 \\
6 & Sistem Informasi & 105 & 1,21 & 5 \\
7 & Sosiologi & 244 & 2,82 & 11 \\
8 & Teknik Industri & 865 & 9,98 & 40 \\
9 & Teknik Informatika & 734 & 8,47 & 34 \\
10 & Teknik Sipil & 1.075 & 12,40 & 50 \\
11 & Arsitektur & 876 & 10,11 & 40 \\
\hline & & 8.667 & 100,00 & 400 \\
\hline
\end{tabular}

\section{ANALISIS DAN PEMBAHASAN}

\section{Sebaran Tempat Tinggal Mahasiswa}

Jumlah mahasiswa yang menjadi responden adalah 400 orang. Seluruh tempat tinggal responden ditunjukkan pada peta sebaran tempat tinggal, seperti yang terdapat pada Gambar 1.

\section{Penggunaan Moda Transportasi}

Dari hasil survei diperoleh moda transportasi yang digunakan oleh mahasiswa. Sebagian besar, sebanyak 57,50\% menggunakan sepeda motor, sedangkan transportasi online sebanyak $19,00 \%$, jalan kaki sebanyak $11,75 \%$, mobil pribadi sebanyak $8,75 \%$, Trans 
Jogja sebanyak $2,25 \%$, dan sepeda sebanyak $0,75 \%$. Rangkuman data ini dapat dilihat pada Gambar 2.

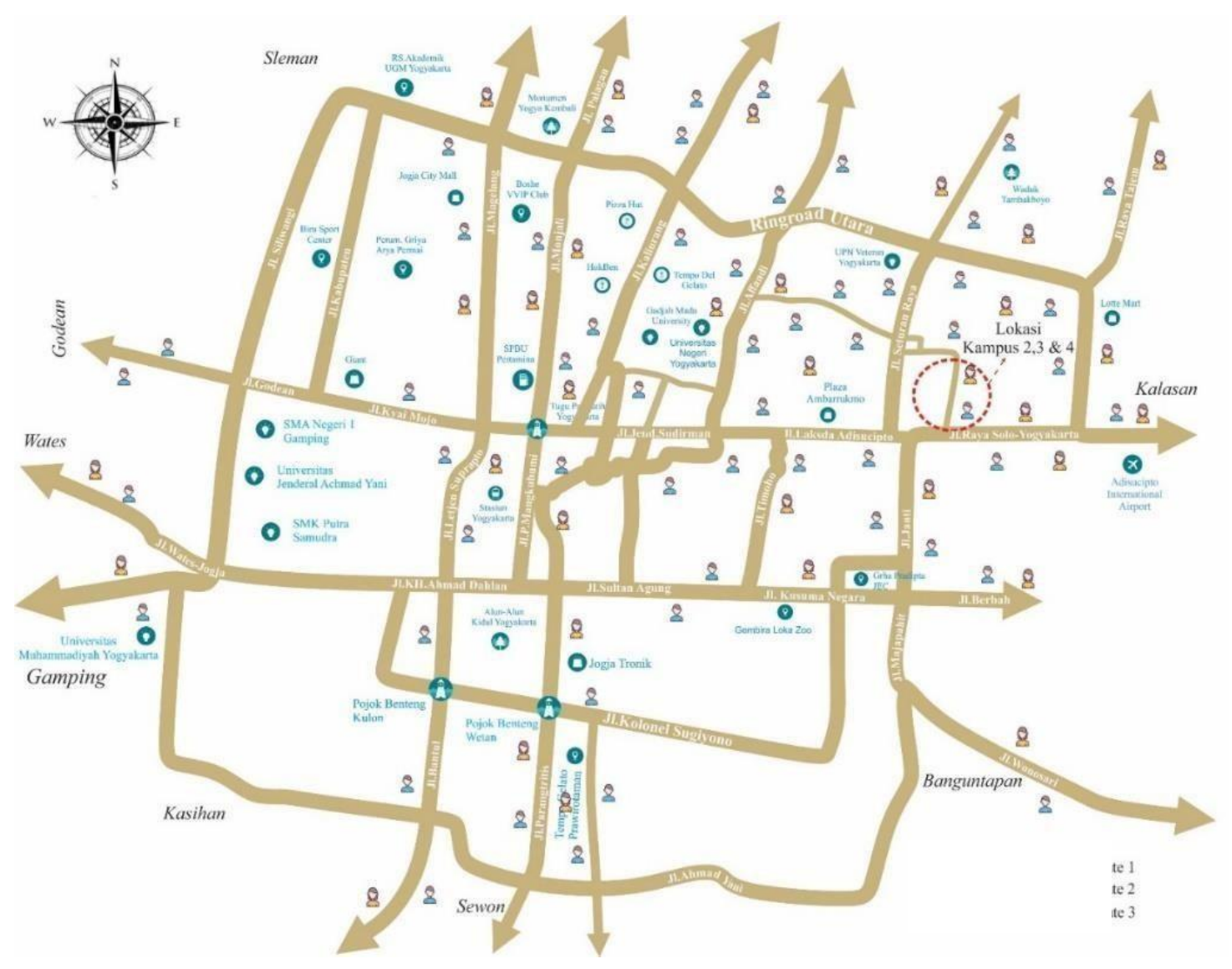

Gambar 1 Peta Sebaran Tempat Tinggal Mahasiswa

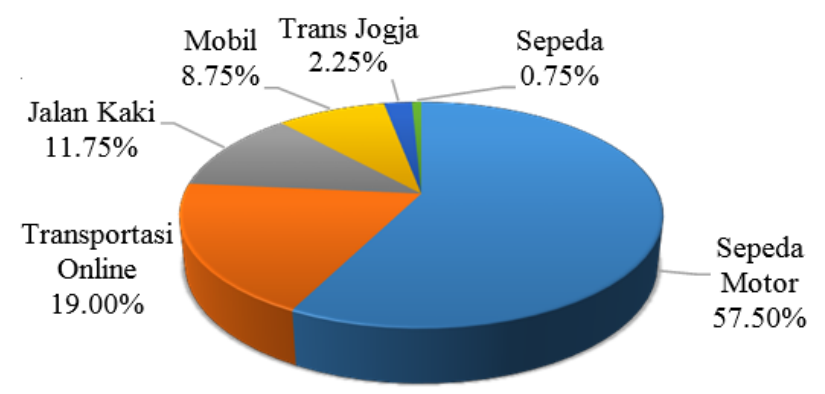

Gambar 2 Proporsi Penggunaan Moda Transportasi

\section{Kemauan Menggunakan Bus Kampus}

Pendapat responden terhadap rencana penyelenggaraan bus kampus khusus Atma Jaya di Babarsari menjadi salah satu pertimbangan penting. Data menunjukkan bahwa sebanyak 268 mahasiswa, atau 67\%, menyatakan setuju dan 132 mahasiswa, atau 33\%, menyatakan tidak setuju, seperti terlihat pada Gambar 3. 


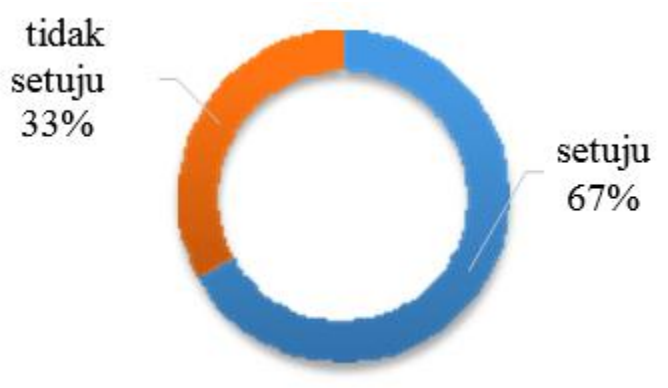

Gambar 3 Proporsi Pendapat Responden

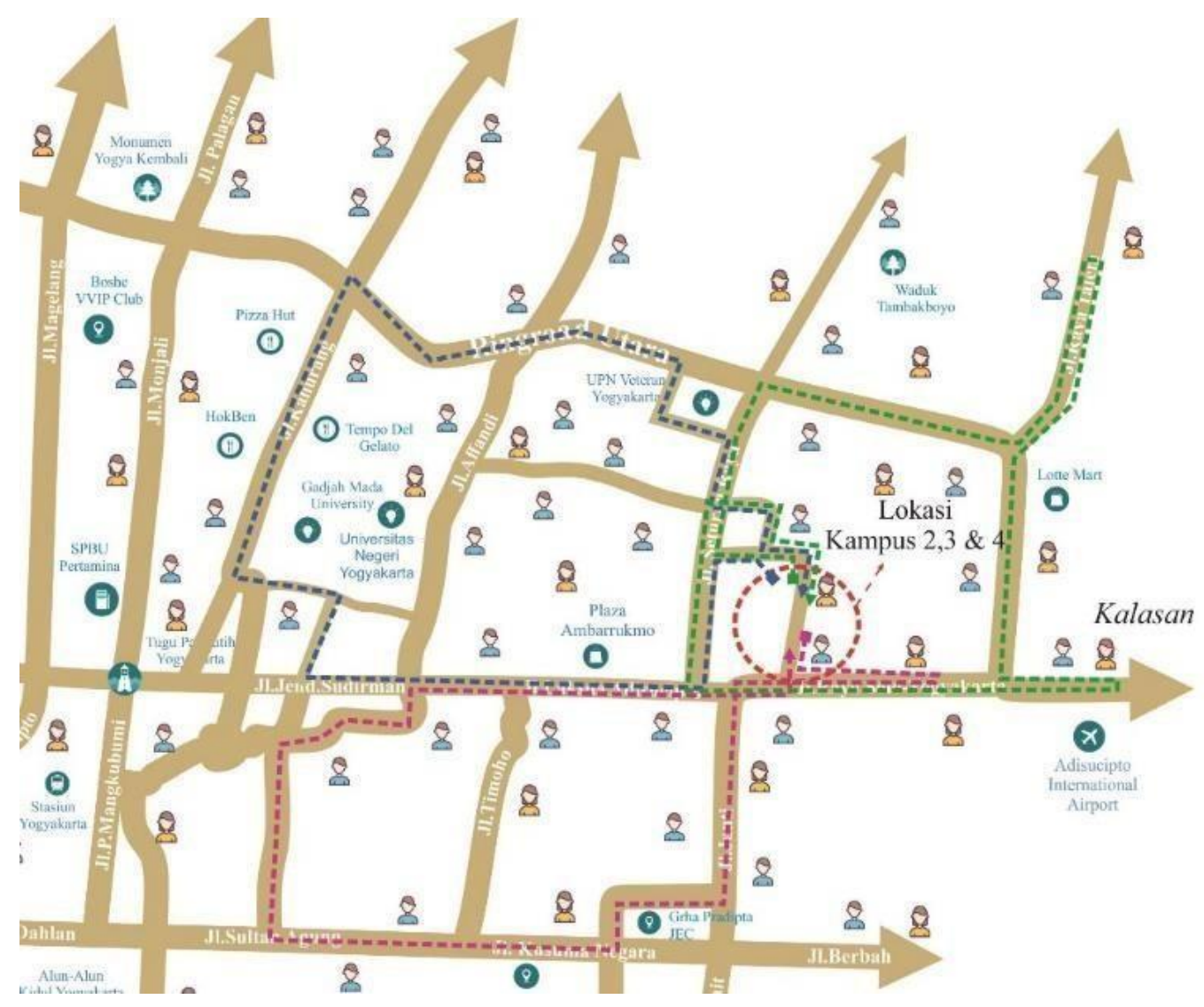

Gambar 4 Diagram Pendapat Responden

\section{Perencanaan Rute Perjalanan}

Rute perjalanan direncanakan dengan pertimbangan waktu sirkulasi kurang dari 1 jam, dengan kecepatan rata-rata perjalanan 20 km/jam. Rute ini juga menghindari jalur-jalur macet dan dapat menjangkau beberapa wilayah tempat tinggal mahasiswa. Dari peta sebaran tempat tanggal mahasiswa, rute perjalanan direncanakan dibagi dalam 3 rute perjalanan, yaitu: 1) Rute 1; Panjang rute 14,6 km, melalui Jln. Babarsari-Jln. Laksda Adisucipto-Jln. Jendral Sudirman-Jln. Prof. Dr. Ir. Herman Yohanes-Jln. Colombo-Jln. Terban-Jln. KaliurangJln. Ringroad Utara-Jln. Perumnas-Jln. Pintu Selatan UPN-Jln. Seturan Raya-Jln. Selokan Mataram-Babarsari. 
2) Rute 2; Panjang rute 13,6 km, melalui Jln. Babarsari-Jln. Seturan Raya-Jln. Ringroad Utara-Jln. Raya Tajem-Jln. Ringroad Utara-Jln. Raya Solo-Yogyakarta-Jln. Laksda Adisucipto-Jln. Kledokan-Jln. Selokan Mataram- Jln. Babarsari.

3) Rute 3; Panjang rute 14,4 km, melalui Jln. Babarsari-Jln. Laksda Adisucipto-Jln. JantiJln. Kusumanegara-Jln. Sultan Agung-Jln. Tunjung-Jln. Dr. Sutomo-Jln. Dr. Wahidin Sudirokusodo-Jln. Munggur-Jln. Laksda Adisucipto-Babarsari.

\section{Menentukan Jumlah Bus Kampus}

Menurut ketentuan Direktorat Jenderal Perhubungan Darat (2002), perhitungan jumlah kendaraan pada suatu jenis trayek ditentukan oleh kapasitas kendaraan, waktu sirkulasi, waktu henti, dan waktu antara. Beberapa asumsi dan batasan digunakan untuk memudahkan perhitungan, yaitu:

1) Jam operasional angkutan kampus disesuaikan dengan jam perkuliahan, yaitu pada pukul 06.00 WIB hingga pukul 18.00 WIB, atau 12 jam.

2) Kapasitas kendaraan adalah 30 tempat duduk.

3) Faktor ketersediaan kendaraan (fA) adalah $100 \%$.

4) Nilai Load Factor dinamis (Lf) adalah nilai standar yang telah ditetapkan, yaitu sebesar $70 \%$ atau 0,70 .

5) Jumlah penumpang adalah $67 \%$ dari jumlah mahasiswa aktif di UAJY dan diasumsikan semua mahasiswa tersebut adalah mahasiswa aktif, yang kuliah dari Hari Senin sampai Hari Jumat. Berikut perhitungan jumlah total penumpang trayek 1, 2, dan 3:

- Jumlah mahasiswa aktif UAJY Babarsari $=8.667$ mahasiswa.

- Mahasiswa yang bersedia berpindah moda sebanyak $67 \%$.

- Total penumpang dalam satu hari $=67 \%$ x $8.667=5.807$ mahasiswa.

- Jadi total mahasiswa per trayek $=(5.806,89 / 3)=1.935,63$ mahasiswa.

- Jam Operasional 06.00-18.00 WIB = 12 jam.

- $\quad$ Total penumpang dalam satu jam $(\mathrm{P} 1)=(1.935,63 / 12)=161,3025 \approx 162$ mahasiswa.

6) Waktu sirkulasi berdasarkan Pedoman Teknis Penyelenggaraan Angkutan Penumpang Umum di Wilayah Perkotaan Trayek Tetap dan Teratur (2002):

$$
\mathrm{CT}_{\mathrm{ABA}}=\left(\mathrm{T}_{\mathrm{AB}}+\mathrm{T}_{\mathrm{BA}}\right)+\left(\sigma_{\mathrm{AB}}+\sigma_{\mathrm{BA}}\right)+\left(\mathrm{T}_{\mathrm{TA}}+\mathrm{T}_{\mathrm{TB}}\right)
$$

dengan:

$\mathrm{CT}_{\mathrm{ABA}}=$ Waktu sirkulasi dari A ke B kembali ke A.

$\mathrm{T}_{\mathrm{AB}} \quad=$ Waktu perjalanan rata-rata dari $\mathrm{A}$ ke $\mathrm{B}$.

$\mathrm{T}_{\mathrm{BA}} \quad=$ Waktu perjalanan rata-rata dari $\mathrm{B}$ ke $\mathrm{A}$.

$\sigma_{\mathrm{AB}}=$ Deviasi waktu perjalanan dari $\mathrm{A}$ ke $\mathrm{B}=5 \% \times \mathrm{T}_{\mathrm{AB}}$.

$\sigma_{\mathrm{BA}} \quad=$ Deviasi waktu perjalanan dari $\mathrm{B}$ ke $\mathrm{A}=5 \% \times \mathrm{T}_{\mathrm{BA}}$.

$\mathrm{T}_{\mathrm{TA}} \quad=$ Waktu henti kendaraan di A.

$\mathrm{T}_{\mathrm{TB}} \quad=$ Waktu henti kendaraan di B.

$\mathrm{T}_{\mathrm{TA}}+\mathrm{T}_{\mathrm{TB}}=10 \% \times \mathrm{T}_{\mathrm{ABA}}$. 
Dari perhitungan tersebut, dengan jumlah penumpang 162 orang/jam, dipilih headway sebesar 15 menit dengan jumlah kebutuhan armada 11 buah. Hal ini dapat dilihat pada Tabel 2.

Tabel 2 Kebutuhan Armada Bus Kampus

\begin{tabular}{|c|c|c|c|c|c|}
\hline \multirow{3}{*}{ Rute Trayek } & \multirow{3}{*}{$\begin{array}{c}\text { Jarak } \\
(\mathrm{km})\end{array}$} & \multirow{3}{*}{$\begin{array}{c}\text { Waktu } \\
\text { Tempuh } \\
\text { (menit) }\end{array}$} & \multirow{3}{*}{$\begin{array}{l}\text { Waktu } \\
\text { Sirkulasi } \\
\text { (menit) }\end{array}$} & \multicolumn{2}{|c|}{ Headway (menit) } \\
\hline & & & & 8 & 15 \\
\hline & & & & \multicolumn{2}{|c|}{ Jumlah Armada } \\
\hline Trayek 1 & 14,6 & 43,8 & 51 & 7 & 4 \\
\hline Trayek 2 & 13,5 & 40,8 & 47 & 6 & 3 \\
\hline Trayek 3 & 14,4 & 43,2 & 50 & 7 & 4 \\
\hline \multicolumn{4}{|c|}{ Kebutuhan Armada } & 20 & 11 \\
\hline
\end{tabular}

\section{Perhitungan Biaya Operasional Kendaraan}

Dengan menggunakan bus Tipe Hino FB 130, diketahui kapasitas bus adalah 30 tempat duduk. Biaya operasional kendaraan menggunakan kebutuhan bus 11 buah. Hasil perhitungan biaya operasional kendaraan disajikan pada Tabel 3.

Tabel 3 Biaya Operasional Bus Kampus

\begin{tabular}{lr}
\multicolumn{1}{c}{ Komponen } & $\begin{array}{r}\text { Biaya Per Bus-Km } \\
\text { (Rp/bus-km) }\end{array}$ \\
\hline A. Karakteristik & \\
Bodi Neptune karoseri Restu Ibu Pusaka & \\
Kapasitas 30 penumpang & 11 \\
Jumlah bus & \\
\hline B. Produksi Per Bus & 14,20 \\
Km tempuh per rit (km) & 8,50 \\
Frekuensi & 120,70 \\
Km tempuh per hari (km) & 13,50 \\
Hari operasi per bulan (hari) & 162,00 \\
Hari operasi per tahun (hari) & $1.629,45$ \\
Km-tempuh per bulan (km) & $19.553,40$ \\
Km-tempuh per tahun (km) & \\
\hline C. Rekapitulasi Biaya Tidak Langsung & 30,97 \\
1 Pajak kendaraan & 157,42 \\
2 Asuransi kendaraan & 30,69 \\
3 Biaya asuransi penumpang & $10.626,19$ \\
4 Biaya awak bus & 168,61 \\
5 Biaya pegawai kantor & 0,23 \\
6 Pajak Bumi dan Bangunan & \\
\hline D. Rekapitulasi Biaya Langsung & $1.253,04$ \\
1 Biaya BBM & 282,86 \\
2 Biaya ban & $1.194,05$ \\
3 Biaya pemeliharaan/reparasi kendaraan & 1,64 \\
4 Biaya pengelolaan & 274,91 \\
\hline Juajak perusahaan & $14.020,62$ \\
\hline
\end{tabular}

Berdasarkan hasil perhitungan Total Biaya Operasional Kendaraan (BOK) sebesar Rp14.020,62/bus-km untuk trayek sepanjang 14,2 km, yang merupakan jarak rata-rata ketiga trayek, pembiayaan selama 1 tahun untuk 1 orang mahasiswa dapat dihitung menggunakan rumus: 
Dari hasil perhitungan tersebut, biaya transportasi yang diperlukan oleh 1 orang mahasiswa dalam satu tahun adalah Rp343.625,71 (untuk kebutuhan 11 kendaraan).

\section{Alternatif Tindak Lanjut Pembiayaan}

Pengadaan bus kampus Universitas Atma Jaya Yogyakarta, sesuai dengan Peraturan Menteri Perhubungan Republik Indonesia Nomor PM 117 Tahun 2018, tentang Penyelenggaraan Angkutan Orang Tidak Dalam Trayek, angkutan sekolah dapat menggunakan kendaraan milik sekolah, kendaraan umum yang disewa dari Perusahaan Angkutan Umum, atau kendaraan umum yang dimiliki oleh Pemerintah Daerah. Dalam hal kendaraan milik sekolah dan disewa dari perusahaan angkutan umum yang ada, pembiayaannya dapat dibebankan pada Sumbangan Pembinaan Pendidikan (SPP) yang diperhitungkan dalam uang tetap per semester. Selain itu, dapat pula bekerjasama dengan Corporate Social Responsibility (CSR) perbankan.

\section{KESIMPULAN}

Berdasarkan hasil penelitian yang telah dilakukan dapat ditarik beberapa kesimpulan sebagai berikut:

1) Rute bus kampus direncanakan dengan pertimbangan waktu sirkulasi tempuh kurang dari 1 jam, dengan kecepatan rata-rata perjalanan 20 km/jam, yang menghasilkan 3 rute, yaitu:

a) Rute 1, dengan panjang 14,6 km dan waktu sirkulasi 51 menit.

b) Rute 2, dengan panjang 13,6 km dan waktu sirkulasi 47 menit.

c) Rute 3, dengan panjang 14,4 km dan waktu sirkulasi 50 menit.

2) Biaya transportasi yang diperlukan oleh satu orang mahasiswa dalam satu tahun adalah sebesar Rp343.625,71 (untuk kebutuhan 11 kendaraan).

3) Pembiayaannya dapat dibebankan pada Sumbangan Pembinaan Pendidikan (SPP) yang diperhitungkan dalam uang tetap per semester atau bekerjasama dengan Corporate Social Responsibility (CSR) perbankan.

\section{UCAPAN TERIMA KASIH}

Ucapan terima kasih disampaikan kepada Lembaga Penelitian dan Pengabdian Masyarakat (LPPM) Universitas Atma Jaya Yogyakarta atas pendanaan penelitian ini, untuk tahun anggaran 2019/2020. 


\section{DAFTAR PUSTAKA}

Basuki, I., Setiadi, A., dan Susanto, B. 2019. Kajian Tarif Pemadu Moda Yogyakarta Internasional Airport. Jurnal Transportasi, 19 (2): 111-120.

Direktorat Jenderal Perhubungan Darat. 2002. Keputusan Direktur Jenderal Perhubungan Darat Nomor SK.687/AJ.206/DRJD/2002 tentang Pedoman Teknis Penyelenggaraan Angkutan Penumpang Umum di Wilayah Perkotaan dalam Trayek Tetap dan Teratur. Jakarta.

Direktorat Jenderal Perhubungan Darat. 2007. Keputusan Direktur Jenderal Perhubungan Darat Nomor SK.967/AJ.202/DRJD/2007 tentang Pedoman Teknis Penyelenggaraan Angkutan Sekolah. Jakarta.

Kementerian Perhubungan. 2018. Peraturan Menteri Perhubungan Republik Indonesia Nomor PM 117 Tahun 2018 tentang Penyelenggaraan Angkutan Orang Tidak Dalam Trayek. Jakarta.

Pemerintah Republik Indonesia. 2009. Undang-Undang Nomor 22 Tahun 2009 tentang Lalu Lintas dan Angkutan Jalan. Jakarta.

Pemerintah Republik Indonesia. 2014. Peraturan Pemerintah Nomor 74 Tahun 2014 tentang Angkutan Jalan. Jakarta. 